\title{
Exercise Testing in Servicemen with Asthma and its application to the assessment of Potential Recruits
}

\author{
Col J Carson \\ MB, FRCP, DTMEH, L/RAMC
}

Maj C R Winfield

MA, BM, MRCP, RAMC*

Army Chest Centre, Cambridge Military Hospital

SUMMARY: A standard exercise test was performed on defined groups of normal and asthmatic personnefw and recruits with a history of childhood asthma. Normal servicemen had a mean Exercise Lability Index (ELI) of 7.81, and we took an ELI of over 15 to be abnormal. By this criterion we found that $91.7 \%$ of service personnel with asthma who could not pass the army Basic Fitness Test (BFT) were abnormal. Conversely among service personnel with asthma with an ELI above 15 we found $89.8 \%$ could not pass the BFT.

Among potential recruits with a history of childhood asthma considered to be in remission we founde $\mathbf{2 7 . 1 \%}$ had minor symptoms and of these $\mathbf{5 1 . 7} \%$ were abnormal. Among potential recruits who admitted 100 symptoms whatever for at least one year $20.5 \%$ were abnormal. We conclude that formal exercise testing $\mathbb{Q}_{f} f_{0}$ recruits with childhood asthma would detect a significant number with abnormal lability likely to interfeje? with military training.

\section{Introduction}

It is recognized that increased bronchial lability can be demonstrated by appropriate exercise testing in asthmatic subjects and in asthmatics in apparent remission ${ }^{1,2}$.

It is also recognized that a history of childhood asthma presents a problem in the assessment of potential recruits ${ }^{3}$ and such a history is present in many who develop asthma during military service.

We have carried out a study of exercise related bronchial lability in service personnel with and without asthma, in asthmatic recruits, and in potential recruits with a history of childhood asthma with a view to assessing the usefulness of a standard exercise test in recruit selection.

Methods

Exercise Test

A standard exercise test was performed in all subjects. This consisted of exercising on a treadmill at six kilometres per hour on a ten degree slope for six minutes. All tests were performed in the morning at ambient temperature in a gymnasium. The temperature range was from $17^{\circ}$ to $25^{\circ}$ Celsius.

The Forced Expiratory Volume in one second $\left(\mathrm{FEV}_{1}\right)$ and Forced Vital Capacity (FVC) were measured using a dry spirometer (Vitalograph Ltd) using the "BTPS" scale. The results were recorded to the nearest 0.5 litres except when a "Vitalo- graph" flow analyser was used when the results we recorded to 0.01 litres.

$\mathrm{FEV}_{1}$ and $\mathrm{FVC}$ were recorded at rest, immediat fyye on completion of exercise, then at one, three, fie seven nine, twelve and fifteen minutes, but continuado up to thirty minutes after exercise if a progressi. fall occurred.

All results were studied to exclude those sugges: tive of a non-maximum expiratory effort.

The subjects had not received either disodium $\overrightarrow{\vec{B}}$ cromoglycate or a bronchodilator on the day of 3 the test.

The resting $\mathrm{FEV}_{1}$ was considered abnormal when it was less than $70 \%$ of the resting FVC.

An "Exercise Lability Index" (ELI) was calculated from the formula:

$$
\text { Highest } \mathrm{FEV}_{1} \longrightarrow \text { Lowest } \mathrm{FEV}_{1}
$$
x 100

Resting $\mathrm{FEV}_{1}$

\section{Subjects}

We divided our subjects into six main groups.

Group 1 A control group of servicemen who? had no history of asthma or hay-fever and whoo had no respiratory illness. They had all success fully completed recruit training.

Group 2 Servicemen who had presented with $\tilde{O}^{-}$ bronchial asthma at some time after completing 
recruit training and who were unable to pass the army "Basic Fitness Test" (BFT) because of exercise induced asthma.

Group 3 Servicemen as defined in Group 2 but who were able to pass the BFT.

Group 4 Recruits who presented with exercise induced asthma in basic military training.

Group 5 Potential recruits with a history of childhood asthma who claimed to be in remission but who, on critical questioning, admitted symptoms of wheeze, however trivial, in the previous year.

Group 6 Potential recruits as defined in Group 5 except that they denied any symptoms of asthma in the previous year despite critical questioning.

We also tested a small number of servicewomen with asthma.

\section{Results}

Group 129 subjects were tested, one twice on different days to produce 30 observations. Ages ranged from 17 to 34 years (mean 20.4) and the resting $\mathrm{FEV}_{1}$ ranged from $3.55 \mathrm{~L}$ to $5.90 \mathrm{~L}$ (mean $4.58 \pm 1.10 \mathrm{~L}$ ). All results were normal at rest. The ELI was between 2.88 and 12.20 (mean $7.81 \pm 5.16$ ).

Group 242 subjects aged from 17 to 41 (mean 27.1) were tested. The resting $\mathrm{FEV}_{1}$ lay between $1.50 \mathrm{~L}$ and $6.50 \mathrm{~L}$ (mean $3.97 \pm 1.80)$ and $10(23.8 \%)$ were abnormal at rest. The ELI was between 6.4 and 68.6 (mean $31.72 \pm 29.96$ ) and only four subjects $(9.5 \%)$ had an ELI below 15 . The distribution of ELI is shown in Figure 1.

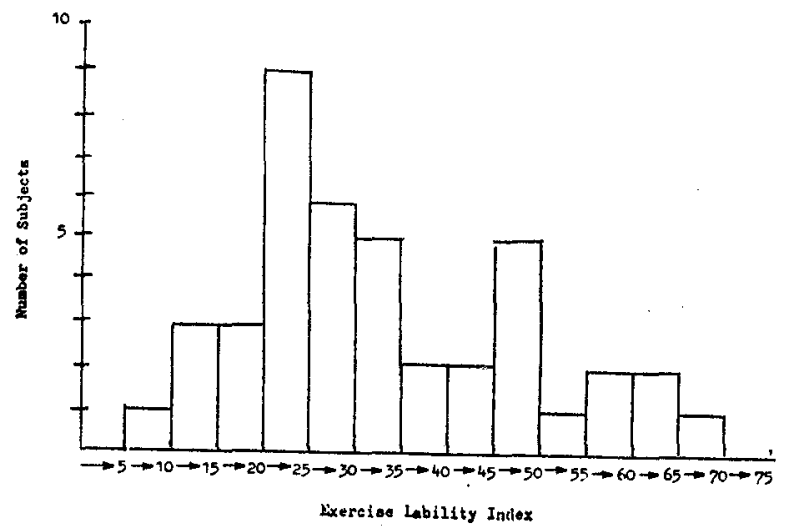

Fig. 1 Distribution of Exercise Lability Index in 42 asthmatic servicemen unable to pass Basic Fitness Test

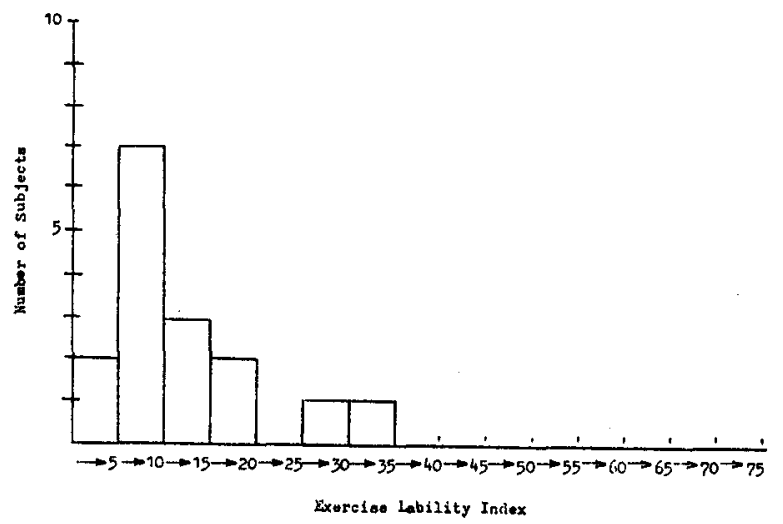

Fig. 2 Distribution of Exercise Lability Index in 16 aesthmatic servicemen who could pass Basic Fitness Test

Group 316 subjects aged from 16 to 38 (mean 22.75) were tested. The resting $\mathrm{FEV}_{1}$ was from $3.10 \mathrm{~L}$ to $5.85 \mathrm{~L}$ (mean $4.48 \pm 1.58 \mathrm{~L}$ ) and two were abnormal at rest $(12.5 \%)$. The ELI was between 3.8 and 30.6 (mean $11.92 \pm 16.3$ ) and was less than 15 in 12 subjects $(75 \%)$. Figure 2.

Group 450 subjects aged from 16 to 21 (mean 17.88) were tested. The resting $\mathrm{FEV}_{1}$ was from? $1.10 \mathrm{~L}$ to $5.35 \mathrm{~L}$ (mean $4.16 \pm 1.72 \mathrm{~L}$ ) and nine werea abnormal at rest $(18 \%)$. The ELI was from 4.210 to 72.7 (mean $25.02 \pm 31.15$ ). The mean ELI of 350 who gave a history of childhood asthma was similaio to that of the group as a whole (25.78). (Figure 3)

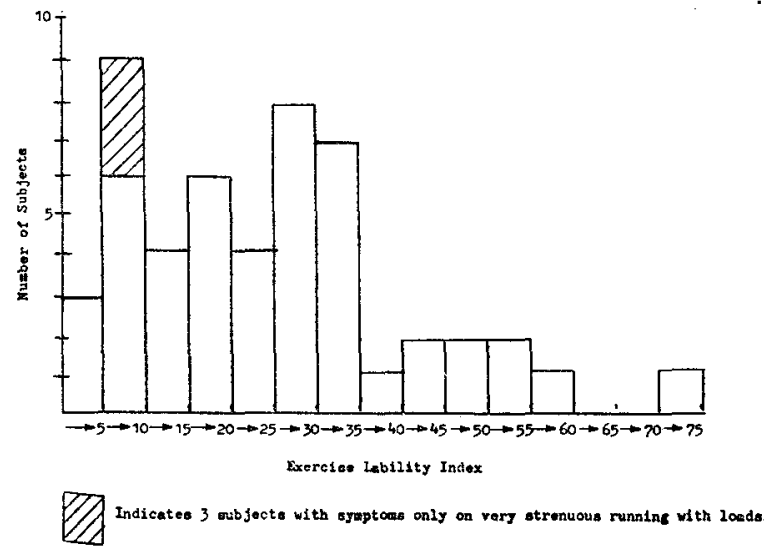

Fig. 3 Distribution of Exercise Lability Index in 50 male recruits developing symptoms of exercise induced asthma during basic training

In this group 16 subjects had an ELI of less than $15(32 \%)$ and three of these with no history of childhood asthma only had symptoms on very strenuous sustained activity. 
Group 529 subjects aged from 16 to 23 (mean 17.55) were tested. The resting $\mathrm{FEV}_{1}$ was from $2.45 \mathrm{~L}$ to $6.15 \mathrm{~L}$ (mean $4.32 \pm 1.69 \mathrm{~L}$ ) and two were abnormal at rest $(6.9 \%)$. The ELI lay between 4.1 and 39.8 (mean $17.55 \pm 19.49$ ) and 14 subjects had an ELI of less than $15(48.3 \%$ ) (Figure 4 ).

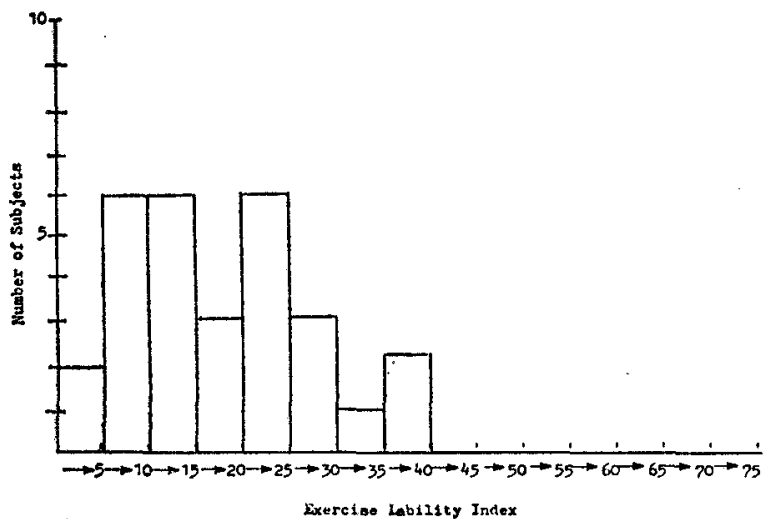

Fig. 4 Distribution of Exercise Lability Index in 29 previously asthmatic recruits referred 'In Remission' but who on close questioning had had minor symptoms in the previous twelve months

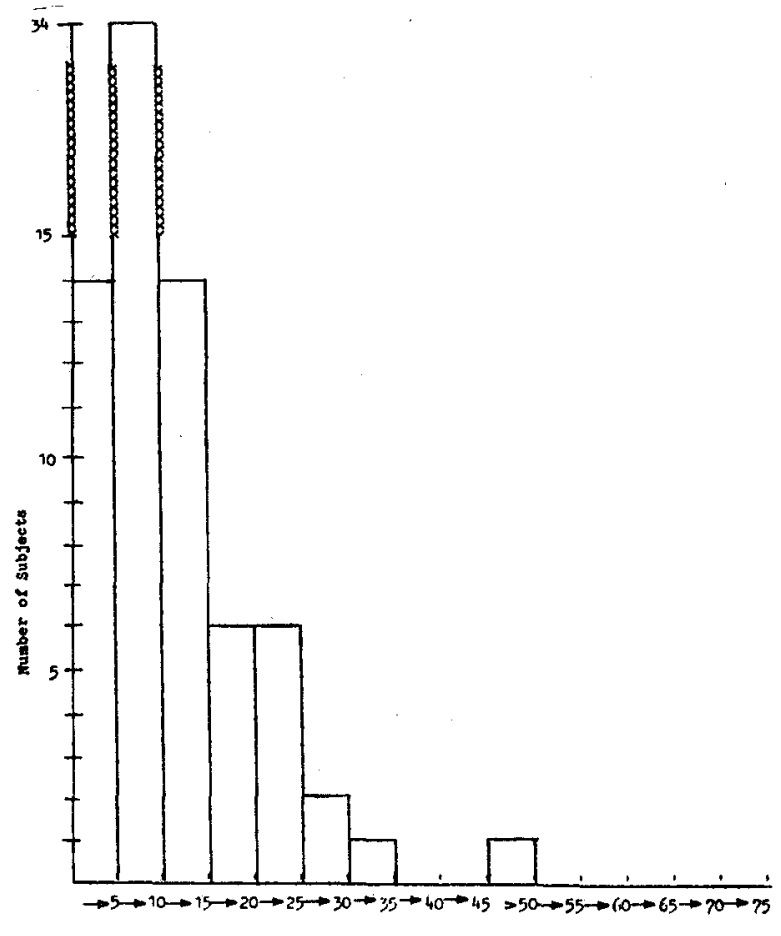

Exercias Lability Intex

Fig. 5 Distribution of Exercise Lability Index in 78 recruits with a history of childhood asthma who appeared to be in complete remission
Group $6 \quad 78$ subjects aged 15 to 25 (mean 18.5) were tested. The resting $\mathrm{FEV}_{1}$ was from $2.75 \mathrm{~L}$ to $6.05 \mathrm{~L}$ (mean $4.48 \pm 1.43 \mathrm{~L}$ ) and six were abnormal $(7.7 \%$ ). The ELI lay from 2.0 to 47.32 (mean $10.93 \pm 15.59)$ and 62 subjects had an ELI of less than $\overline{15}(79.5 \%)$ (Figure 5 ).

\section{Servicewomen}

We also tested three servicewomen with mild asthma who could pass the BFT. Two had a normal ELI and one an ELI of 16.36.

A further six servicewomen who could not pass a BFT because of wheeze had a range of ELI from 22.16 to 73.13 (mean 38.3 ).

The proportions of servicemen, all serving personnel and potential recruits with ELI above and below $15 \%$ are shown in Table 1.

\section{Discussion}

Treadmill testing has been shown to be a reliable method of demonstrating increased bronchial lability and standard methods and patterns of response are described ${ }^{4}, 5,6$.

The level of exercise chosen was one likely tơ 응 demonstrate changes in bronchial lability under con:0 trolled conditions and to be within the capabilitie? of apparently well recruits. Only two subjects were unable to complete the protocol, one developing asthma at two mintes, the other chest pains whiclo prevented further exercise.

We did not adopt the practice of a second perio of exercise following bronchodilator aerosol inhala tion to increase lability as we wished to keep the procedure as simple as possible.

We consider it important that the FEV 1 and FVC results are checked carefully to exclude variable and non-maximum effort otherwise spuriously high lability results may be obtained. In only seven cases were the results so inconsistent as to be unanalysable.

Published results for normal bronchial lability have produced results higher than those described here. Results will vary with the method used however.

Our experience suggests that individuals with lability well over $20 \%$ may only have symptoms during the sustained physical activity required for military training, and others who deny childhood asthma have a history of "wheezy bronchitis" if asked.

We therefore felt it appropriate to define our own normal range in a group with no relevant past history and who had completed basic military training uneventfully. These subjects were either technicians in the clinical measurements department or orthopaedic patients undergoing remedial physiotherapy. None experienced any difficulty performing the test. 
We have thus defined a range of normal exercise bronchial lability with a mean of 7.81 and a standard deviation $(n-i)$ of 2.58. A conventional upper limit of normal would be 12.97 (mean $+2 \mathrm{SD}$ ) and it would be highly unlikely that a normal result would exceed 15.55 (mean + 3SD).

In discussing our results we have taken an ELI of over 15 to be abnormal.

\section{Lability in Asthmatic Subjects}

In the group of asthmatic servicemen who could not pass the BFT only $10(23.8 \%)$ had an abnormal resting vitalograph. A small number of servicemen in low medical category with chronic persistent wheeze were deliberately not tested. In contrast several individuals in this group had little or no incapacity in everyday activity and sports including football, badminton and squash although they were often aware of some wheeze during these activities. Characteristically these subjects failed their BFT during the "Best Effort" run, that is after 6 to 10 minutes sustained running.

Figure 1 shows the distribution of ELI in this group. The ELI exceeded 20 in 35 subjects $(83.6 \%)$ and exceeded 15 in 38 subjects $(90.5 \%)$.

Thus in known asthmatic servicemen there is a good correlation between an ELI above 15 and failure in the BFT. In the six servicewomen with asthma who could not pass the BFT all had an ELI above 15 so that overall $91.7 \%$ of 48 service personnel unable to pass the BFT had an ELI of more than 15. (Table 1.) symptoms had developed three months earlier on return to UK in November from Hong Kong. He complained of wheeze when not running his habitual 10 to 12 miles daily. His resting $\mathrm{FEV}_{1}$ rose from $3.1 \mathrm{~L}$ to $3.55 \mathrm{~L}(14.5 \%)$ on exercise, falling to $2.6 \mathrm{~L}$ $(16.1 \%$ ) after exercise (ELI 30.6). Clearly some individuals with asthma can cope with the demands of exercise despite abnormal lability, but they are probably exceptional.

Increased exercise induced bronchial lability is only one aspect of bronchial asthma and will differ in degree between individuals ${ }^{2}$ although it has been suggested that most if not all asthmatics will show an abnormal response to an exercise or cold hyperventilation test if this is severe enough ${ }^{8,}, 9$.

The test which we used at ambient indoor temperature will not identify all subjects with abnormal bronchial lability. Nevertheless we feel there is a useful correlation between our results and ability to pass the BFT. Of the total of 67 asthmatic serving personnel tested 48 had a lability of over 15 and of these $44(91.7 \%)$ could not pass the BFT. In 43 of them the ELI exceeded 20 and $41(95.4 \%)$ could not pass the BFT.

We feel that these observations in service personnel justify the view that an individual with ano ELI above 15 is unlikely to meet the army standard of basic fitness. An individual with an ELI above 20 is highly unlikely to do so.

Lability in Recruits

This group had all been passed fit at pre-service and initial medical examination. Thirty five of them

Table 1

Distribution of normal and abnormal Exercise Lability Index in groups of asthmatic subjects

\begin{tabular}{lccc}
\hline \multicolumn{1}{c}{ GROUP } & ELI up to 15 & ELI above 15 & Total \\
\hline Asthmatic Servicemen who failed BFT & $4(9.5 \%)$ & $38(90.5 \%)$ & 42 \\
All Asthmatic Personnel who failed BFT & $4(8.3 \%)$ & $44(91.7 \%)$ & 48 \\
Asthmatic Servicemen who passed BFT & $12(75 \%)$ & $4(25 \%)$ & 16 \\
$\begin{array}{l}\text { All Asthmatic Personnel who passed BFT } \\
\begin{array}{l}\text { Potential Recruits with Childhood Asthma and minor } \\
\quad \text { symptoms in past year }\end{array}\end{array} \quad 14(73.7 \%)$ & $5(26.3 \%)$ & 19 \\
$\begin{array}{l}\text { Potential Recruits with Childhood Asthma who denied } \\
\text { all symptoms in past year }\end{array}$ & $14(48.3 \%)$ & $15(51.7 \%)$ & 29 \\
\hline
\end{tabular}

Not all asthmatic personnel however fail their BFT and these subjects had lower labilities (Figure $2)$. Of these servicemen only four $(25 \%)$ were abnormal by our criteria and only two had an ELI above 20. Both these subjects had an abnormal resting $F E V_{1}$. One had a lability, entirely a fall of 29.2, despite having passed a BFT six months earlier. The other was a marathon runner aged 38 whose had a past history of asthma and about half of these had been referred for specialist opinion. Only two had been exercise tested, both by us and both were normal and remained normal on re-testing.

Many of the group were referred with symptoms which developed on exercise much more strenuous than that demanded by the BFT, for example 5 to 10 mile runs in battle order. Three subjects, 
indicated in figure 3, only developed symptoms on completion of such a 10 mile run. Thus the broader spread of results with more normal labilities is not surprising.

The results however suggest that up to $68 \%$ might have been identified prior to enlistment if an exercise test had been done prior to the preservice medical examination.

\section{Lability in Potential Recruits in Remission}

Of the 108 potential recruits tested all but two claimed to have had only mild childhood symptoms, with little or no time off school, no hospital admission, or prolonged periods of treatment of any sort. All claimed to be in remission and had been considered normal at initial or pre-service examination, being referred in accordance with Pulheems regulations.

By critical direct questioning we obtained histories of wheeze, however trivial, in 29 subjects in the previous year. As shown in figure 4, we found 15 $(51.7 \%)$ of this group were abnormal.

The distribution of ELI was quite different in the 78 who denied all symptoms after close questioning (figure 5). Nevertheless $16(20.5 \%)$ were abnormal by our criteria.

\section{Conclusion}

A separate analysis of potential recruits in apparent remission has shown no relationship between duration of remission, atopic history, age of subject, smoking habit and the finding of an ELI above $15^{10}$. Critical questioning will reveal some symptoms in a proportion of individuals who claim to be in remission.

Nevertheless a number of individuals with a history of childhood asthma who appear to be in complete remission, often playing sport at school with no problem, will have an ELI of an order which we feel is unlikely to be compatible with the performance of military training.

Some of the subjects we considered abnormal had an abnormal resting $\mathrm{FEV}_{1}$, but the majority were normal at rest. We feel therefore that when recruits with a past history of asthma are being assessed, those not found to have asthma after a careful history and resting ventilation tests should undergo a formal exercise test as a substantial number will prove to be abnormal and unsuitable for service.

\section{Acknowledgements}

We wish to thank the technicians in the clinical measurement department who carried out most of the exercise tests.

\section{REFERENCES}

1 TREFoR Jones $\mathbf{R} \mathbf{H}$ and Jones $\mathbf{R} \mathbf{S}$. Ventilator capacity in young adults with a history of asthma is childhood. Brit Med J 1966; II: 976-8.

2 Martin a J, Landau L I and Phelan P D. Lun@ function in young adults who had asthma in childo hood. Am Rev Respir Dis 1980; 122: 609-16.

3 Pulheems. A Joint Service System of Medica费 Classification. 1976; 0420(b).

4 Anderson S D, Silverman M, Konig AND Godfrey S. Exercise Induced Asthma. Brit Dis Chest 1975; 69: 1-39.

5 Cropp G J E. The Exercise Provocation Testo Standardisation of procedures and evaluation of response. I Allergy Clin Immunol 1979; 6: 627-33\%

6 Study Group on Exercise Challenge, Americarb Academy of Allergy. Guidelines for the methodology of exercise challenge testing of asthmatics. J Allerg: Clin Immunol 1979; 6: 642-5.

7 Burr M L, Eldridge B A AND Borysiewicz L Ka Peak expiratory flow rates before and after exercis in school children. Arch Dis Childh 1974; 49: 923-6.

8 Haynes $R$ L, Igram $R$ H and MCFadden E Rत̃ An assessment of the pulmonary responses to exercise in asthma and an analysis of the factors influencing it. Am Rev Respir Dis 1976; 114: 799-52.

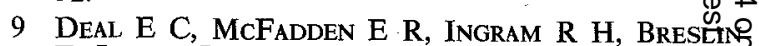
$F \mathrm{~J}$ AND JAEGER $\mathrm{J} J$. Airways responsiveness to cold air and hyperpnoea in normal subjects andōir those with hay fever and asthma. Am Rev Reso $i$ s Dis 1980; 121: 621-8.

10 WINFIELD C AND CARSON J. Bronchial lability asthmatics in remission - In preparation. 